\title{
Virtualização de Jogos Educativos: Uma Experiência no Ensino de Matemática
}

\author{
Title: Educational Games Virtualization: An Experience on Mathematics Teaching
}

Wilk Oliveira dos Santos

Universidade Federal de Alagoas

wos@ic.ufal.br

\author{
Clovis Gomes da Silva Junior \\ Universidade de Pernambuco \\ clovis.gomes@upe.br
}

\begin{abstract}
Resumo O uso de jogos digitais na educação já está cunhado como um mecanismo capaz de auxiliar o processo de ensino e aprendizagem, tendo sua aplicação discutida em diversos aspectos. Neste sentido, um dos aspectos abordados atualmente é a Virtualização de Jogos para o ensino, tendo por objetivo criar versões digitais para jogos tradicionais, mantendo os aspectos pedagógicos e psicopedagógicos da versão tradicional do jogo, atrelados as mecânicas contemporâneas dos jogos digitais. Neste contexto, este artigo tem por objetivo apresentar os resultados do processo de Virtualização de Jogos em dois jogos tradicionais usados no ensino de Matemática. Estes jogos foram avaliados em termos de usabilidade e aspectos pedagógicos. Os resultados alcançados permitiram constatar que os jogos foram eficazes como mecanismo de apoio ao processo de ensino e aprendizagem de conteúdos especificos da disciplina de Matemática, bem como o processo de Virtualização de Jogos se mostrou eficaz para virtualizar jogos capazes de auxiliar no processo de ensino e aprendizagem.
\end{abstract}

Palavras-Chave: Jogos Educativos; Virtualização de Jogos Educativos; Avaliação de Jogos Educativos

\begin{abstract}
The use of games in education is actually addressed as a mechanism capable to help the teaching and learn process, and its application in the field of education is discussed in different aspect. In this sense, an aspect discussed is the Game Virtualization to the teaching. This process aims to create digital versions to traditional games, keeping the pedagogical and psychological aspects from the traditional version, linked with the contemporary game design mechanicals. Thus, this paper aims to shows the results of Game Virtualization Process applied in order to develop two traditional game used in the Mathematic' teaching. The result allowed to identify that the games were effective as mechanism to support the teaching and learn of specific Mathematic' contents, as well to foment the Game Virtualization Process as a process capable to development effective games to auxiliary the teaching and learn process.
\end{abstract}

Keywords: Educational Games; Educational Games Virtualization; Educational Games Evaluation 


\section{Introdução}

Com o transcorrer das gerações, diversas pesquisas, como [10], [19], [37], [36], [33], [35] e [2] dentre outras, apresentaram pesquisas discutindo a aplicação e/ou desenvolvimento de jogos como mecanismo de apoio ao processo de ensino e aprendizagem de algum conteúdo especifico.

No contexto destes trabalhos, são discutidos pontos de vista variados, sobre tipos de jogos e sua aplicação na educação. [10] por exemplo, aborda os jogos como um elemento cultural, o reconhecendo como algo inato ao homem e mesmo aos animais, considerando-o uma categoria absolutamente primária da vida, logo, anterior a cultura.

Neste sentido, de acordo com [19], os jogos possuem sentido de elemento que permeia o processo cognitivo humano, fazendo ainda uma divisão classificatória destes jogos quanto ao seu objetivo, os mesmos são por ele classificados em: jogos de exercício, de construção, simbólicos e de regras.

Nesta perspectiva, haja vista [37], os jogos são elementos não compartimentados e não operados segundo o sistema das disciplinas escolares, não se decompondo absolutamente em processos separados, correspondendo às diferentes matérias, entre as quais se reparte a aprendizagem escolar.

Neste contexto, vislumbrando a perspectiva da Teoria dos Campos Conceituais, [36] aborda os jogos, como um conjunto de situações cujo domínio progressivo exige uma variedade de conceitos e de representações simbólicas em estreita conexão. Neste sentido, as pesquisas supracitadas são corroboradas ainda por [33] que discute o uso de jogos em âmbito diretamente educacional, destacando o uso de jogos em sala de aula.

Assim, os jogos são vistos também como agente motivador de aprendizagem, ou elemento capaz de transcorrer de um conhecimento prévio para uma requisição de novos conceitos, haja vista, as percepções de [35]. Assim, para [2], os jogos são artefatos capazes de estimular os estudantes a buscar novos paradigmas de aprendizado, se tornado autores de sua própria aprendizagem.

Finalmente, estas pesquisas demostram que os jogos são vistos como mecanismo educacional, capaz de proporcionar aos estudantes e professores, uma aprendizagem colaborativa e divertida, por meio da ludicidade que estes contêm.

Ao mesmo tempo, é sabido que a sociedade contem- porânea é caracterizada pelo uso cada vez mais frequente das tecnologias digitais da informação e comunicação (TDIC) na organização das mais diferentes práticas sociais, como aponta [22]. Nesse contexto, o investimento em tecnologias e a presença das mesmas em salas de aula é cada vez maior. Comumente, encontram-se nas escolas, laboratórios de informática ou até mesmo com os próprios estudantes, dispositivos como notebooks, tablets, smartphones, entre outros [27].

Assim, a integração destas tecnologias no ambiente escolar, possibilita discussões quanto aos métodos e práticas sobre o uso destas ferramentas no auxilio ao processo de ensino e aprendizagem [31]. Neste sentido, é importante buscar alternativas, para, através do uso destas tecnologias, obter maneiras de facilitar o processo de ensino e aprendizagem.

No entanto, observa-se na discussão sobre o uso de jogos na educação, que podem existir também fatos negativos, para [8], mesmo um jogo bem projetado pode ter algumas desvantagens como: se não for bem aplicado perde o objetivo; nem todos os conceitos podem ser explicados por meio dos jogos; se o professor interferir com frequência, perde a ludicidade e; se o aluno for obrigado a jogar por exigência do professor, o mesmo fica contrariado.

Nesta perspectiva, experiências como as de [4], que abordam o processo de "virtualização do saber", destacam a substituição das atividades tradicionais, por atividades realizadas através de tecnologias digitais. Estes trabalhos destacam inclusive que os professores, por vezes se sentem impotentes ao levar um jogo tradicional a sala de aula, e os estudantes não aderirem a atividade. Estes estudantes, de acordo com [28], se sentem mais atraídos por atividades ligadas as TDIC em detrimento aos meios tradicionais.

Neste contexto, com o objetivo de minimizar esta dificuldade, observam-se na literatura, trabalhos que tratam da Virtualização de Jogos Educativos. De acordo com [28] e [24], através deste processo, é possível unir os princípios pedagógicos e psicopedagógicos contidos nos jogos tradicionais, outrora usados de forma positiva no ensino, às as mecânicas contemporâneas dos jogos digitais.

Nesta perspectiva, este artigo objetiva apresentar um estudo, realizado nos últimos 4 anos por pesquisadores no âmbito de Virtualização de Jogos. Este trabalho selecionou um conjunto de 8 jogos tradicionais usados de forma positiva no ensino da Matemática (selecionados através de uma pesquisa anterior realizada pelo mesmo grupo [26]), a fim de serem analisados e submetidos ao 
processo de Virtualização de Jogos.

Assim, dois jogos foram escolhidos e submetidos ao processo de Virtualização de Jogos, sendo ainda avaliados por estudantes e professores, esta avaliação ocorreu em termos de interface gráfica (usabilidade) e em termos de aprendizagem. A pesquisa foi caracterizada como uma avaliação multi-perspectiva focada no cliente e no especialista.

Neste contexto, este artigo traz um apanhado completo da realização do trabalho, descrevendo o processo de pesquisa, escolha dos jogos, bem como seus processos de virtualização, aplicação e avaliação. $\mathrm{O}$ estudo traz como principais resultados, o desenvolvimento de dois jogos para utilizados no ensino de Matemática, além da proposta de um processo para a virtualização de jogos, englobando desde a escolha do jogo até a aplicação e avaliação multi-perspectiva do mesmo.

Finalmente, os resultados da avaliação em ambiente controlado, mostram que os jogos foram efetivos em termos de usabilidade e aprendizagem, podendo serem utilizados no ensino da disciplina de Matemática, bem como, o processo de Virtualização de Jogos Educativos utilizado, mostrou-se eficaz no desenvolvimento destes jogos.

\section{Embasamento Teórico}

A seguir será apresentado o embasamento teórico desta pesquisa, destacando o processo de Virtualização de Jogos, Avaliação de Jogos Educativos, especialmente relacionada a Avaliação de Interface e da Avaliação Pedagógica, além dos principais trabalhos relacionados.

\subsection{Virtualização de Jogos Educativos}

Com base nos trabalhos de [24], [26] e [5], em síntese, o processo de Virtualização de Jogos consiste em criar versões digitais para os jogos tradicionais, outrora usados de forma positiva no ensino de determinado conteúdo. O processo visa manter os aspectos pedagógicos e psicopedagógicos da versão tradicional, ao mesmo tempo em que estes aspectos estejam atrelados as mecânicas contemporâneas dos jogos digitais.
Neste contexto, o Processo de Virtualização dos Jogos ora abordado, segue o modelo de Virtualização de Jogos, proposto por [24], que trata-se de uma adaptação do processo de desenvolvimento de softwares de [32], voltada a virtualização de jogos. Contudo, são observadas determinadas especificidades com relação a cada um dos jogos, especialmente em suas respectivas avaliações.

Neste sentido, o processo de Virtualização de Jogos adotado, em uma visão de alto nível compreende as seguintes atividades: $(i)$ o jogo a ser virtualizado deve ser escolhido mediante avaliação pedagógica de profissionais da área de aplicação do jogo, (ii) caso o jogo escolhido possua versão digital, a mesma deve ser avaliada em torno de seus aspectos computacionais de interface, e seus aspectos pedagógicos, de modo que consiga-se definir se o mesmo já atende ou não seus objetivos pedagógicos e psicopedagógicos.

Ainda, (iii) o processo de desenvolvimento do jogo deve ser antecedido por reuniões com profissionais da disciplina em questão, além de profissionais da Pedagogia e da Psicologia, que tem a função de determinar aos profissionais de Computação (designers de interface e programadores), os critérios que devem ser mantidos no jogo, a fim de que o mesmo, mantenha os aspectos pedagógicos e psicopedagógicos da versão tradicional e (iv) o jogo desenvolvido só deve ter seu processo considerado encerrado, uma vez que o mesmo seja avaliado e validado em torno de sua interface e estrutura pedagógica, tendo para isto que atingir os mesmos objetivos pedagógicos da sua versão tradicional.

Assim, o processo supracitado deve ocorrer por meio de equipe multidisciplinar, com a participação de professores da disciplina em questão além de profissionais da área de Psicologia, responsáveis por analisar e propor soluções para facilitar a interação dos estudantes e professores com os jogos, bem como manter os conceitos pedagógicos e psicopedagógicos contidos na versão tradicional do jogo, além de profissionais de Pedagogia e Computação, responsáveis por atrelar os aspectos pedagógicos a interface do jogo, como aconselha [28].

\subsection{Avaliação de Jogos Educativos}

Seguindo o raciocínio de [23], a avaliação de jogos é caracterizada como uma das fazes mais importantes do seu processo de desenvolvimento, pois a mesma permite aferir o quão bom ou adaptável é o jogo diante do cenário de sua aplicação. Assim, nos jogos educativos em especial, destaca-se a importância de uma avaliação mais robusta que a dos jogos tradicionais, visto que o mesmo precisa ser avaliado em seus aspectos de interface, semelhante 
aos jogos comerciais e ser avaliado em relação a seus aspetos pedagógicos, como abordado por [16].

Deste modo, [25] aponta a importância de uma avaliação que contemple os aspectos computacionais de interface e também os pedagógicos dos jogos educativos, ao mesmo tempo que [7] propõe que os softwares educativos em geral (dos quais estão inseridos os jogos educativos), antes de serem levados a sala de aula de forma definitiva, possam ser avaliados em aspectos de interface, a fim de perceber se os elementos gráficos que compõem a interface do jogo são agradáveis aos usuários, e nos aspetos pedagógicos a fim de perceber se os objetivos pedagógicos propostos pelo jogo estão sendo atingidos.

\subsubsection{Avaliação de Interface}

A interface de um software pode ser entendida como a parte de um sistema computacional com a qual uma pessoa entra em contato - física, perceptiva ou conceitualmente - com o software [14]. Assim, de acordo com [21], a avaliação de interface pode ser caracterizada como a análise de princípios bem definidos, que sejam capazes de proporcionar aos usuários uma sensação agradável e prazerosa durante o uso do software.

Neste contexto, no que cerne a avaliação de jogos educativos, esta é de suma importância, haja vista as afirmações de [11]: quanto mais cedo forem encontrados os problemas de interação ou de interface, menor o custo de se consertá-los, e mais chances o jogo tem de tornar a experiência do usuário o mais agradável possível.

Neste sentido, diversos objetivos devem ser alcançados durante a avaliação de interface de um jogo educativo, dos quais destacam-se aqueles lançados por [20] e [9]: (i) identificar as necessidades de usuários ou verificar o entendimento dos projetistas sobre estas necessidades, (ii) identificar problemas de interação ou de interface, (iii) alcançar objetivos quantificáveis em métricas de usabilidade e (iv) investigar como uma interface afeta a forma de trabalhar dos usuário. É importante que busquese obedecer a estes critérios durante avaliação dos jogos educativos, assim como neste trabalho.

\subsubsection{Avaliação Pedagógica}

A avaliação pedagógica dos jogos educativos tem por objetivo identificar se o mesmo atinge os objetivos pedagógicos que se propõe a alcançar [24]. Neste sentido, [24] destaca ainda que a mesma deve ser definida segundo critérios bem definidos com a colaboração de profissionais da área de domínio do jogo que estiver sendo avaliado.
Neste contexto, para [23] a avaliação pedagógica deve permitir aos estudantes e professores envolvidos no processo de avaliação, dialogar sobre o jogo, expondo suas dificuldades e percepções sobre o jogo e sobre o conteúdo, de modo que possa-se perceber de forma intrínseca se o jogo conseguiu abordar fidedignamente o que se propunha.

Nesta perspectiva, [15] destaca ainda que existem diferentes tipos de abordagens usadas para avaliação de objetos de aprendizagem, especialmente os jogos educativos, bem como, cabe ao pesquisador determinar a melhor estratégia de acordo com o tipo de objeto, público alvo e cenário da avaliação.

\subsection{Trabalhos Relacionados}

Inicialmente, [4] tratam da "virtualização do saber" abordando a união necessária entre o tradicional e o digital, destacando em uma abordagem teórica a lacuna existente entre o tradicional e o digital, apontando o processo de desuso dos jogos tradicionais em comparação aos jogos digitais. Contudo, [3] abordam em seu trabalho, a virtualização do esporte, fazendo uma análise entre os processos de virtualização esportiva, ligados aos jogos eletrônicos, sua interferência na cultura corporal de movimento e quais as possíveis implicações para a Educação Física.

Nesta perspectiva, estes trabalhos tratam dos avanços tecnológicos em detrimento dos objetos tradicionais, abordando ainda os problemas causados no âmbito educacional pelo esquecimento do tradicional em função dos avanços tecnológicos, corroborando e reafirmando a realização deste trabalho.

Por sua vez, [34] apresentam o processo de desenvolvimento de um jogo (apresentado como jogo presencial) utilizado em diversas práticas de ensino de Matemática em nível regional de um conjunto de cidades de um estado Brasileiro, o mesmo foi desenvolvido à luz da teoria da aprendizagem significativa, dentro da perspectiva de um grupo que analisa objetos de aprendizagem e suas implicações nos processos de ensino e aprendizagem em ciências exatas e busca disponibilizar estes objetos na região onde foi aplicado o trabalho.

No entanto, o trabalho supracitado apresenta resultados regionalizados, não oportunizando a disponibilização dos jogos para outros interessados. O jogo tradicional foi desenvolvido por pesquisadores da instituição, não apresentando nenhuma metodologia correlacionada à escolha do mesmo. Não é apresentada nenhuma preocupação quanto à metodologia de desenvolvimento abordada, excerto observações quanto à linguagem de programação utilizada. Também não apresenta nenhuma avaliação ou 
validação do software em ambiente educacional.

Por sua vez, [39] tratam da aprendizagem colaborativa em caráter presencial e remoto, dissertando a respeito das oportunidades geradas pelas inovações tecnológicas quanto a comunicação interpessoal, discutindo soluções para a interação em ambientes colaborativos presenciais e remotos, usando recursos para a comunicação interpessoal (chat, áudio e videoconferência) com Realidade Aumentada (RA). O seu trabalho é baseado na criação de uma versão digital para jogos tradicionais, utilizando recurso de RA.

O trabalho, porém não apresenta preocupações quanto à escolha dos jogos, ou ao seu processo de desenvolvimento, focando apenas nos aspectos tecnológicos da Realidade Virtual e Aumentada.

Neste âmbito, o estudo gerador deste artigo diferencia-se dos demais, pelo fato de ter uma metodologia que se preocupou com o processo de escolha do jogo, seu processo de desenvolvimento, sob a ótica da Virtualização de Jogos, além da aplicação e avaliação do mesmo, preocupando-se com seus aspectos de interface gráfica (usabilidade) e pedagógicos.

\section{Metodologia}

A metodologia do estudo ora apresentado foi desenvolvida com os objetivos de: $\boldsymbol{a}$ ) identificar jogos tradicionais usados de forma positiva no ensino da Matemática, b) separar dois destes jogos para serem submetidos ao processo de Virtualização de Jogos Educativos, $\boldsymbol{c}$ ) submeter estes jogos ao processo supracitado e $\boldsymbol{d}$ ) submeter os jogos que foram virtualizado a uma avaliação multiperspectiva (usabilidade e aprendizagem).

Neste sentido, a metodologia (processo de virtualização) proposto foi divida em três etapas principais, sendo cada uma delas, subdivida em outras etapas, sendo as principais: $(\boldsymbol{i})$ pesquisa, (ii) desenvolvimento e (iii) avaliação.

A etapa de pesquisa preocupou-se em realizar uma busca por jogos tradicionais, que tenham sido usados de forma positiva no ensino da Matemática, e que tenham sido totalmente, ou parcialmente descartado da sala de aula em função dos avanços tecnológicos, objetivando escolher um grupo de jogos, a fim de que estes fossem analisados individualmente para serem escolhidos dois jogos e estes serem submetidos ao processo de virtualização. A etapa de pesquisa foi divida em $(i . i)$ pesquisa acadêmica, (i.ii) pesquisa web e (i.iii) pesquisa ao livro didático acadêmico e (i.iv) análise individual dos jogos.

A etapa de desenvolvimento, teve por objetivo, desenvolver os produtos finais destes trabalhos, incluído os protótipos, e os jogos (desenvolvidos completamente), prontos para serem submetidos à avaliação. Neste sentido, a mesma foi subdividida em: (ii.i) levantamento de requisitos, (ii.ii) design de interface e (ii.iii) programação.

Por sua vez, a etapa de avaliação preocupou-se com uma avaliação que englobasse os aspectos de interface/usabilidade dos jogos e suas nuances pedagógicas, assim, esta etapa foi dividida em (iii.i) avaliação de interface (usabilidade) (iii.ii) avaliação pedagógica, estas etapas. A Figura 1 apresenta o processo descrito.

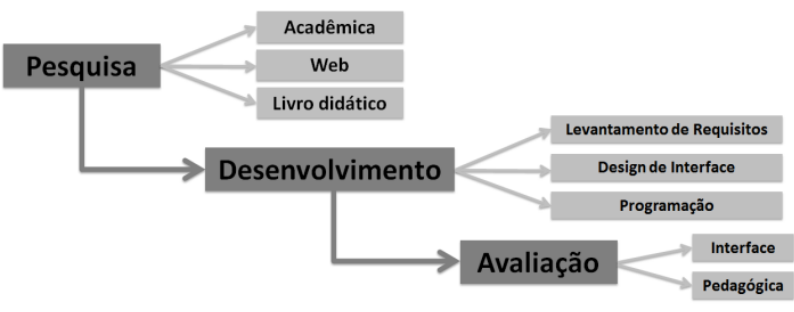

Figura 1: Etapas do Processo de Virtualização de Jogos Educativos

\subsection{Pesquisa}

A etapa de pesquisa dividiu-se em outras três etapas: (i) pesquisa acadêmica, (ii) pesquisa web e (iii) pesquisa ao livro didático acadêmico. As etapas previamente mostradas tiveram o objetivo comum de buscar jogos tradicionais que tenham sido usados com resultados positivos na disciplina de Matemática, e por ventura, tiveram o seu uso em sala de aula descontinuado, em função dos avanços tecnológicos, para então definir dois jogos á serem submetidos ao Processo de Virtualização.

No intuito de minimizar riscos em relação a identificação de resultados, a etapa de pesquisa foi conduzida por foi conduzida por dois profissionais, sendo um estudante de graduação em Licenciatura em Computação (formação em Computação e Pedagogia), responsável pela pesquisa e análise inicial dos dados, e um professor doutor em Matemática, com longa experiência na área, responsável por solucionar conflitos em relação a identificação dos dados. Para uma revisão completa desta etapa do estudo, ver [24].

\subsubsection{Pesquisa Acadêmica}

Buscaram-se nesta etapa, trabalhos que contemplassem ações em relação ao uso de jogos tradicionais usados no ensino da Matemática, disponíveis em bases acadêmicas (ACM Digital Library, Elsevier, IEEE Xplore, Scopus, Springer, etc.), além dos trabalhos publicados nos 
anais dos eventos: Congresso Brasileiro de Informática da Educação (CBIE), Congresso da Sociedade Brasileira de Computação (CSBC), ambos entre os anos de 2003 e 2013. Assim, optou-se por pesquisar apenas textos completos nestas bases citadas seguindo o pensamento apresentado por [38] que as colocam como bases relevantes de buscas, além da classificação dos mesmos, disponibilizada plataforma CAPES ${ }^{1}$.

\subsubsection{Pesquisa Web}

$\mathrm{Na}$ web, realizou-se a mesma busca anterior, porém em bases de dados na internet, optou-se por utilizar a plataforma de buscas google, com o objetivo de encontrar-se jogos tradicionais usados no ensino da Matemática, além de outros tipos de trabalhos relacionados que pudessem nos levar a trabalhos ligados a nosso eixo de pesquisa.

\subsubsection{Pesquisa ao Livro Didático Acadêmico}

Neste momento da pesquisa, analisaram-se os livros "Matemática Magia y Mistério", "Mais Jogos e Atividades Matemáticas do Mundo Inteiro" e "Le Dictionnare Pemguin des curosites géométriques", que tratam de jogos para o ensino da Matemática e apresentam uma série de jogos tradicionais usados de forma positiva no ensino da Matemática, os livros antes mencionados foram selecionados por meio de especialistas (professores doutores com ênfase de pesquisa em livro didático pedagógico).

Assim, esta etapa foi viabilizada, em função da observação feita por parte dos profissionais de Matemática. Os mesmo afirmaram que é relevante a pesquisa ao livro didático acadêmico, por saber-se que como aponta [29] o livro didático vem sendo usado com mais frequência no Brasil desde a década de 1960, além de acreditar-se que o livro didático, ainda vem ocupando um papel central no cenário acadêmico, mesmo diante das novas tecnologias. Os livros usados foram assim escolhidos em função da análise e sugestão destes profissionais.

\subsection{Resultados da Pesquisa}

A pesquisa realizada teve como resultados, um mapeamento com uma série de jogos tradicionais outrora usados de forma positiva no ensino da Matemática, bem como uma análise dos tipos de jogos encontrados e dos resultados gerados a partir destes jogos (para uma visão condessada, ler [24]).

\footnotetext{
${ }^{1}$ Para maiores informações, consultar: https://qualis.capes.gov.br/
}

Ainda no cerne destes resultados, a etapa de pesquisa permitiu inicialmente encontrar e separar um quantitativo de oito jogos que atendessem aos requisitos da pesquisa (Tabela 1), estes jogos foram analisados de forma individual pelos profissionais que participaram deste projeto, de modo a escolher-se dois jogos para serem submetidos ao processo de virtualização.

\begin{tabular}{l} 
Jogos tradicionais não disponíveis em \\
versão digitais \\
\hline Conquistando com o Resto \\
\hline O retorno \\
\hline Desafios com Palitos \\
\hline Ziguezague \\
\hline Os copos \\
\hline ConTIG \\
\hline Jogo das Diagonais \\
\hline
\end{tabular}

Tabela 1: Jogos tradicionais não disponíveis em versão digital

\subsubsection{Análise e Escolha dos Jogos}

A primeira seleção dos jogos, ocorreu a partir da análise individual de todos os jogos encontrados nas fases anteriores da pesquisa, (ver Tabela 1).

Neste sentido, os jogos anteriormente selecionados, foram analisados de forma individual pelos mesmos profissionais anteriormente mencionados. Esta avaliação ocorreu por meio de discussões abertas onde cada profissional pode dissertar a respeito de cada um dos jogos e discutir quais deles eram mais apropriados para passar pelo processo, e por fim, de acordo com as discussões, qualificar e classificar os jogos analisados.

Neste contexto, posteriormente, os profissionais envolvidos, tiveram a oportunidade de realizar uma votação com o intuito de fazer a escolha definitiva dos dois jogos. Neste sentido, os dois jogos escolhidos foram: Conquistando com o Resto e Desafios com Palitos. Esta classificação ocorreu por meio das reuniões anteriormente mencionadas.

\subsubsection{Jogo Conquistando com Resto}

O jogo consiste em um tabuleiro com 48 casas, numeradas de forma não sequencial. Os jogadores começam o jogo na casa 43 (primeira casa do tabuleiro) e jogam sequencialmente um dado em formato de cubo (um jogador por vez) dividindo o valor da casa em que se encontra (incialmente casa 43) pelo valor que for obtido no dado, em seguida avança exatamente o quantitativo de casas correspondente ao resto desta divisão (Figura 2).

Por exemplo: caso o jogador esteja na casa 43 e no dado seja sorteado 4 , divide-se 43 (valor da casa) por 4 
(valor do dado) e avança a quantidade de casas correspondente ao resto dessa divisão, que é 3 . Neste caso o jogador iria para a casa 15 (terceira casa do tabuleiro), vence o jogo quem chegar à casa 96 (última casa do tabuleiro) primeiro, como pode ser observado na Figura 2, que mostra o jogo em sua versão tradicional.

Este jogo era usado como mecanismo de apoio ao ensino de divisão, propiciando aos estudantes uma forma lúdica e divertida de compreender de forma implícita ao jogo determinados conceitos fundamentais a operações de divisão [24].

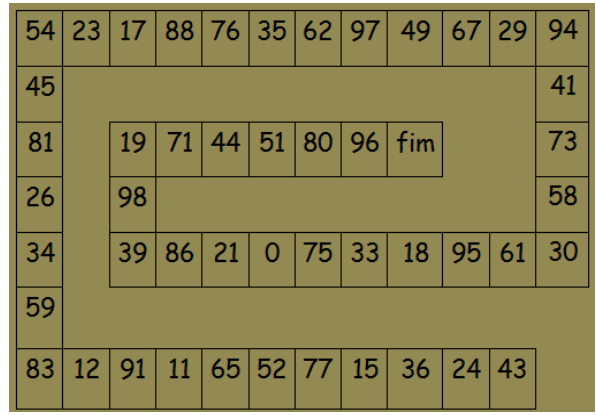

Figura 2: Conquistando com Resto (versão tradicional/manual)

\subsubsection{Jogo Desafios com Palitos}

O jogo Desafios com Palitos trata-se de um tradicional jogo, usado como instrumento de ensino para uma série de conceitos da disciplina da Matemática. Assim, o jogo consiste basicamente em resolver desafios Matemáticos por meio da movimentação de palitos dispostos em alguma superfície plana.

Neste contexto, dependendo de como seja usado por professores e estudantes, o jogo pode abordar diferentes tipos de conteúdos, como Algarismos Romanos, Conversão de Valores, Raciocínio Lógico, entre outros. Este jogo pode ser jogado de forma individual, em duplas, ou mesmo em equipes de jogadores. Destaca-se, que este jogo já existe em versões digitais, para computadores pessoais e aparelhos mobile, porém, de acordo com a avaliação realizada nos mesmos (ver seção 3.6), estes carecem de aspectos relacionados à interface e pedagógicos.

Neste sentido, o jogo Desafios com Palitos virtualizado por este grupo de pesquisadores, se preocupa com estes aspetos, não se eximindo de utilizá-los e avaliá-los [25]. A Figura 3 apresenta este jogo em sua versão tradicional.

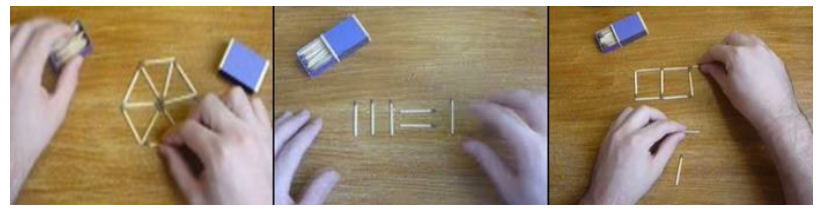

Figura 3: Jogo Desafios com Palitos (versão tradicional/manual) ${ }^{1}$

\subsubsection{Processo de Virtualização do jogo Con- quistando com o Resto}

No que cerne o desenvolvimento, (processo de virtualização) do jogo Conquistando com o Resto, a priori foi realizada a análise de requisitos, onde professores da disciplina de Matemática, enfatizaram como ocorre o uso do mesmo em sala de aula e destacaram suas estruturas matemáticas.

Posteriormente, os profissionais de Pedagogia e Psicologia descritos em sessão anterior, puderam definir como deveria ficar a versão digital do jogo, contemplando uma mecânica que permitisse um uso agradável e satisfatório por parte de estudantes e professores, ao mesmo tempo, que mantivesse os aspectos, pedagógicos e psicopedagógicos da versão original/tradicional do jogo, fundamentais para que a versão digital do mesmo seja usada como recurso de apoio ao processo de ensino e aprendizagem da disciplina de Matemática.

Após tais definições, deu-se início a fase de desenvolvimento (desenvolvimento de interface gráfica e programação) do jogo. $\mathrm{O}$ mesmo foi dividido em 4 (quatro) telas:

- Tela Inicio: Na tela inicio os jogadores tem sua primeira interação com o jogo, os mesmos podem escolher o percurso inicial que irão percorrer no jogo (Figura 4).

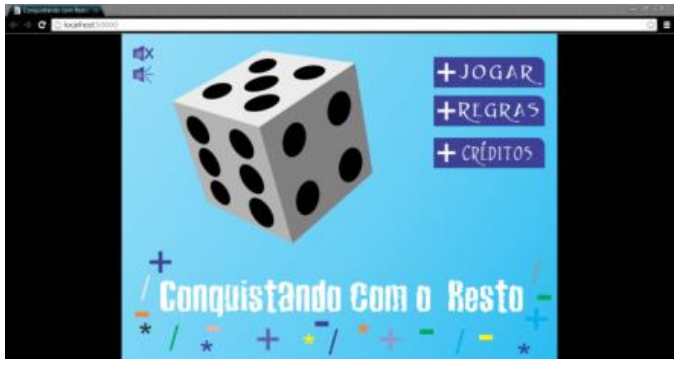

Figura 4: Conquistando com Resto (tela inicio)

- Tela Créditos: Tela que apresenta as informações dos desenvolvedores da versão digital do jogo (Figura 5).

\footnotetext{
${ }^{1}$ Imagens retiradas a partir de capturas de tela do vídeo contido no seguinte link: http://migre.me/p2 fB6
} 


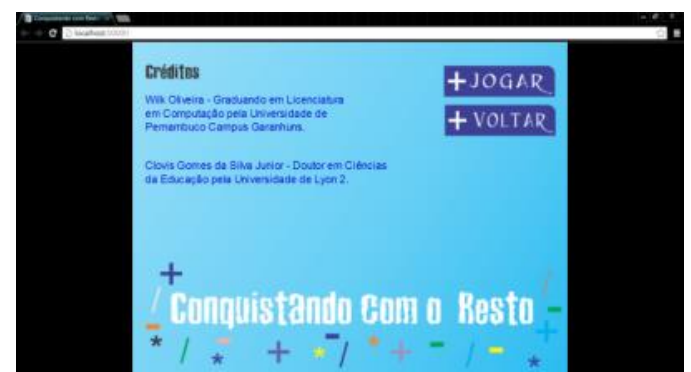

Figura 5: Conquistando com Resto (tela créditos)

- Tela Regras: Nesta tela são apresentadas as regras do jogo e exemplos que devem auxiliar os jogadores na execução do mesmo (Figura 6).

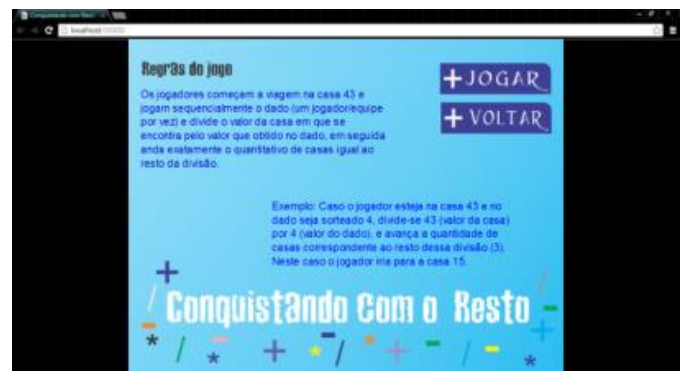

Figura 6: Conquistando com o Resto (tela regras)

- Tela Jogo: Nesta tela é apresentado o jogo. Esta assume fundamental importância para o mesmo, pois é nela que se encontra o objeto principal do software desenvolvido, “o jogo" (Figura 7).

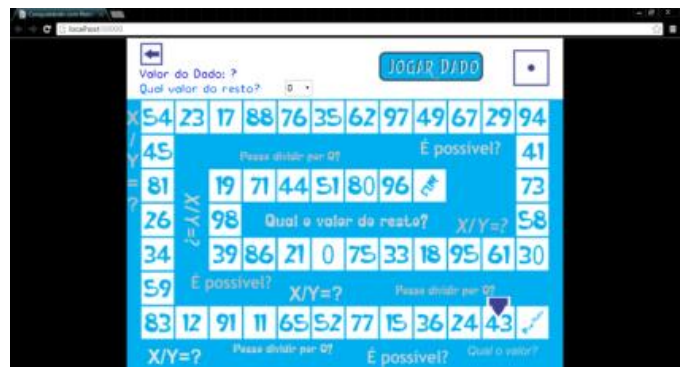

Figura 7: Conquistando com Resto (tela jogo)

\subsubsection{Processo de Virtualização do jogo De- safios com Palitos}

Além das etapas descritas para a virtualização do jogo Conquistando com o Resto, para o Processo de Virtualização do jogo Desafios com Palitos, em observação ao fato de o mesmo, já ter sido desenvolvido em versões digitais, optou-se por fazer ainda, uma comparação entre as versões digitais já existentes, com o objetivo de avaliar-se se os mesmo obedecem aos critérios de interface gráfica e aspetos pedagógicos necessários (ver Tabela 2).
Neste sentido, em função da quantidade de etapas do jogo, e dos diferentes tipos de desafios apresentados, optou-se por fazer uso da Teoria da Carga Cognitiva (TCC), que em conformidade com [18], refere-se ao processamento humano de informações, ou seja, um conjunto de princípios que geram um ambiente de aprendizagem eficaz, aumentando o processo de cognição do ser humano. Ainda de acordo com [18], esta teoria tem como objetivo tornar a interação humana com a tecnologia mais alinhada ao processo cognitivo.

No que cerne as análises de softwares similares, foram analisados quatro jogos, dos quais, dois para dispositivos móveis e dois para uso online em computadores pessoais: (i) Puzzle de Fósforos ${ }^{1}$ (ii) Matchsticks ${ }^{2}$ (iii) Palitos: Racha a cuca ${ }^{3}$, e (iv) Jogo dos palitos ${ }^{4}$. Estes jogos foram analisados em relação aos seus aspectos de usabilidade e processos cognitivos, considerando de modo especial os princípios de atenção, memória e percepção de [20].

As analises foram realizadas por três estudantes de Licenciatura em Computação (com formação em Computação e Pedagogia) e um profissional em IHC (mestre), as análises nos elementos que compõem estes princípios são mostrados na Tabela 2 .

\begin{tabular}{l|l}
\hline \multicolumn{2}{c}{ Análise de Jogos Similares } \\
\hline Informações salientes & $\begin{array}{l}\text { Uso de cores para } \\
\text { destacar palavras e } \\
\text { figuras }\end{array}$ \\
& (X) Matchstick Puzzle \\
(X) Matchstick Puzzle & $(X)$ Matchstick \\
(X) Matchstick & (X) Racha a Cuca \\
(X) Racha a Cuca & $(X)$ Jogo dos Palitos \\
(X) Jogo dos Palitos & $\begin{array}{l}\text { Interface sobrecarre- } \\
\text { gada de informações }\end{array}$ \\
\hline Informações apresenta- & \\
das de forma sequencia- & ( ) Matchstick Puzzle \\
da Matchstick Puzzle & ( ) Matchstick \\
(X) Matchstick & (X) Racha a Cuca \\
(X) Racha a Cuca & Faz uso de efeitos \\
(X) Jogo dos Palitos & sonoros \\
\hline Faz uso de ícones &
\end{tabular}

Tabela 2: Análise de Jogos Similares

Os resultados apresentados na Tabela 2 mostram que alguns problemas relevantes foram identificados nos

\footnotetext{
${ }^{1}$ Para maiores informações, consultar: http://migre.me/kjgM4

${ }^{2}$ Para maiores informações, consultar: http://migre.me/kjh4i

${ }^{3}$ Para maiores informações, consultar: http://migre.me/kjhaT

${ }^{4}$ Para maiores informações, consultar: http://migre.me/kjhfF
} 
jogos encontrados, e por conseguinte, foram solucionado no jogo desenvolvido. O jogo Racha a Cuca por exemplo, apresenta uma interface carregada de informações, prejudicando o entendimento por parte dos usuários, Ambos os jogos apresentam cores para destacar palavras, ao mesmo tempo em que fazem uso de ícones, no mesmo jogo, podendo assim, sobrecarregar a quantidade de informações para seus jogadores.

O jogo desenvolvido é composto por dez fases, abordando assuntos como: conversão de valores, algarismos romanos e raciocínio lógico, entre outros. A Figura 8 mostra a tela inicial do jogo e as fases 6 e 8 que abordam, respectivamente, raciocínio lógico e trigonometria básica.
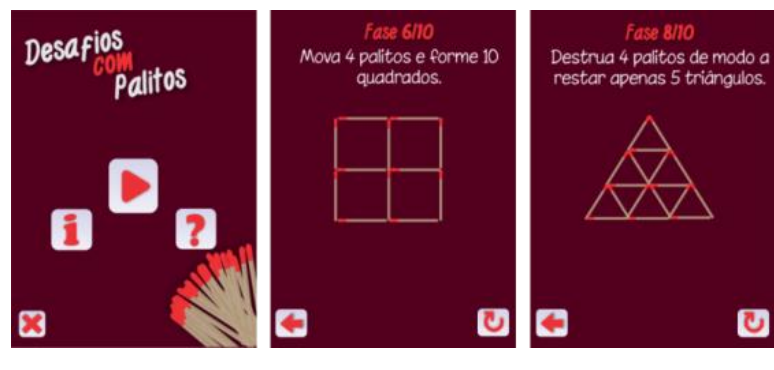

Figura 8: Interface Gráfica do Jogo Desafios com Palitos

\section{Avaliação}

Esta etapa do estudo teve como objetivo realizar uma avaliação multi-perspectiva, focada no cliente (estudantes) e no especialistas (professores da disciplina de Matemática). Neste sentido, ambas as avaliações foram realizadas por estudantes integrantes de uma turma da $5^{\text {a }}$ série $/ 6^{\circ}$ ano, de uma escola pública estadual, situada no Agreste do estado de Pernambuco. Foram convidados aleatoriamente dez estudantes de uma turma composta por 30 estudantes para avaliação do jogo Conquistando com o Resto e 15 estudantes para avaliação do jogo Desafios com Palitos.

Neste contexto, a turma foi escolhida de acordo com os descritores da disciplina de Matemática. A quantidade de estudantes foi definida de acordo com os espaços físicos disponíveis para a realização do experimento, e por representar uma amostra significativa diante da quantidade total de estudantes da turma $(\mathrm{N}=30)$. A quantidade de participantes também facilitou a avaliação dos rascunhos dos estudantes, de acordo com [23] extremamente importantes na avaliação pedagógica. [17] também comprova a efetividade dos resultados da avaliação de interface diante da quantidade de participantes.

A avaliação de interface foi realizada em caráter quantitativo, fazendo uso da Escala de Likert [12] que permite mostrar qual o grau de concordância e/ou discordância do usuário em relação aos elementos funcionais de determinado objeto.

Para cada jogo foram definidas uma série de questões assertivas seguindo o modelo da Escala de Likert e baseadas nos conceitos de [17], [20] e [9]: (ver seção 2.2.1). As questões foram definidas pelos profissionais de Interação Humano-computador (IHC) que colaboram com este projeto.

A avaliação pedagógica por sua vez, seguindo a abordagem de [23], foi realizada de forma qualitativa, procurando focar na observação das jogadas e nos diálogos dos estudantes durante e depois de jogar. Assim, cada estudante, antes de começar a jogar, recebeu uma folha de rascunho, de modo que pudesse a usar, sempre que necessário, para ajudar na resolução dos desafios do jogo. Esta folha foi posteriormente analisada pelo professor de Matemática, que por meio da visualização dos rascunhos, pode realizar observações quanto ao jogo e sua eficácia.

Neste contexto, a Avaliação Pedagógica de cada jogo ocorreu por meio das análises do professor em cada folha de rascunho bem como da análise do professor aos diálogos realizados entre os estudantes em sala de aula durante a aplicação do jogo. Estas análises foram discutidas pelo professor e demais profissionais envolvidos na pesquisa.

Para que os jogos pudessem ser considerados validados e por conseguinte serem liberados para uso em sala de aula, espera-se que estes recebam uma avaliação média igual ou superior a $70 \%$ (considerado estatisticamente relevante) em todas as questões na avaliação de interface, bem como atingir seus objetivos pedagógicos, sendo esta última avaliação feita de acordo com as análises dos professores de Matemática responsáveis por esta avaliação.

\subsection{Avaliação de Interface do jogo Conquis- tando com o Resto}

Para a realização da avaliação de interface deste jogo, os estudantes responderam a um total de 8 questões (assertivas), as questões envolveram itens de interface relacionados à aprendizagem, memorização e conforto visual.

Foram apresentadas aos estudantes as seguintes assertivas: (1) $\mathrm{O}$ jogo reconhece meus toques no mouse e teclado (2) As cores do jogo são agradáveis (3) Entendi o que cada ícone representa (4) A interface possui informações de fácil entendimento (5) Entendi rapidamente o que deveria fazer no jogo (6) É mais fácil aprender matemática com o jogo Conquistando com o Resto (7) O jogo é motivador e me deixou com vontade de continuar (8) 
Instalaria o jogo no meu computador ou dispositivo móvel e recomendaria a um amigo.

Para cada uma das assertivas apresentadas, os estudantes puderam escolher entre cinco diferentes alternativas. As opções disponibilizadas para cada uma das questões foram: Concordo Fortemente (CF); Concordo (C); Indeciso (I); Discordo (D); Discordo Fortemente (DF). Na Tabela 3 são aprestados os resultados colhidos durante a avaliação.

\begin{tabular}{c|c|c|c|c|c}
\hline \multicolumn{6}{c}{ Resultados Quantitativos da } \\
\hline $\begin{array}{c}\text { Assertiva/ } \\
\text { Opção }\end{array}$ & $\mathrm{CF}$ & $\mathrm{C}$ & $\mathrm{I}$ & $\mathrm{D}$ & $\mathrm{DF}$ \\
\hline 1 & $20 \%$ & $60 \%$ & $10 \%$ & $10 \%$ & $0 \%$ \\
\hline 2 & $10 \%$ & $60 \%$ & $30 \%$ & $0 \%$ & $0 \%$ \\
\hline 3 & $40 \%$ & $20 \%$ & $30 \%$ & $10 \%$ & $0 \%$ \\
\hline 4 & $20 \%$ & $40 \%$ & $40 \%$ & $0 \%$ & $0 \%$ \\
\hline 5 & $20 \%$ & $20 \%$ & $50 \%$ & $10 \%$ & $0 \%$ \\
\hline 6 & $50 \%$ & $50 \%$ & $0 \%$ & $0 \%$ & $0 \%$ \\
\hline 7 & $50 \%$ & $40 \%$ & $10 \%$ & $0 \%$ & $0 \%$ \\
\hline 8 & $70 \%$ & $30 \%$ & $0 \%$ & $0 \%$ & $0 \%$ \\
\hline
\end{tabular}

Tabela 3: Conquistando com o Resto (avaliação quantitativa de interface)

Os resultados obtidos nesta etapa da avaliação oportunizaram perceber que o jogo reconhece os movimentos e toques realizados pelos jogadores, tornando fácil a realização de jogadas e a aceitação dos estudantes em relação às cores do jogo, tornado agradável o ato de jogar $\mathrm{e}$, por conseguinte, corroborando para que o mesmo possa permanecer por mais tempo no jogo.

O entendimento por parte dos jogadores no que cerne os ícones e representações presentes no jogo, bem com a presença de poucos itens e informações de interface foi outro fato que permitiu aferir a boa jogabilidade presente no jogo.

Por outro lado, a maioria dos jogadores não compreenderam de forma rápida o que deveria fazer no jogo. Esta informação nos permitiu indagar se o problema relacionado a esta percepção estava no fato do jogo não dispor de mecanismos que permitissem esta compreensão por parte dos estudantes, ou se esta problemática estava ligada aos conhecimentos prévios dos estudantes em relação ao conteúdo abordado, visto que se pôde observar que o jogo apresenta poucas informações de interface e cores agradáveis, proporcionado fácil entendimento do mesmo. Contudo, optou-se por desenvolver um tutorial (em formato de animação interativa), de modo a facilitar a interpretação e entendimento por parte dos estudantes, no intuito de atender estas dificuldades.

Percebeu-se ainda, de acordo com os dados desta avaliação que a maioria absoluta dos estudantes, concordou que foi mais fácil compreender os assuntos de Matemática com o uso do jogo, assim como acreditam que o mes- mo é motivador e os instigam a permanecer por mais tempo no jogo.

A maioria absoluta concordou também que instalaria o jogo em seu dispositivo móvel, ou em seu computador, demostrando que os mesmos se mostraram satisfeitos com o jogo, motivados para continuar a jogar e dispostos a continuar a aprender os conceitos apresentados no jogo.

\subsection{Avaliação de Interface do jogo Desafios com Palitos}

Seguindo o mesmo modelo de avaliação computacional de interface que jogo anterior, os profissionais de IHC, definiram a seguinte sequência de assertivas: (1) O jogo reconhece meus toques na tela e movimenta corretamente os palitos. (2) As cores do jogo são agradáveis. (3) Entendi o que cada ícone representa. (4) A interface possui poucas informações e as mesmas são de fácil entendimento. (5) Entendi rapidamente o que deveria fazer nos desafios do jogo. (6) Os desafios do jogo são motivadores e me deixa com vontade de continuar. (7) Me senti satisfeito ao conseguir resolver os desafios.

A exemplo da avaliação do jogo anterior, para cada questão assertiva, foram apresentados as seguintes opções: Concordo Fortemente (CF); Concordo (C); Indeciso (I); Discordo (D); Discordo Fortemente (DF). Os resultados obtidos com esta avaliação, são dispostos na Tabela 4.

\begin{tabular}{c|c|c|c|c|c}
\hline \multicolumn{5}{c}{ Resultados Quantitativos da } & Interface \\
\hline $\begin{array}{c}\text { Assertiva/ } \\
\text { Opção }\end{array}$ & CF & C & I & D & DF \\
\hline 1 & $35 \%$ & $55 \%$ & $10 \%$ & $0 \%$ & $0 \%$ \\
\hline 2 & $40 \%$ & $20 \%$ & $20 \%$ & $20 \%$ & $0 \%$ \\
\hline 3 & $45 \%$ & $25 \%$ & $20 \%$ & $10 \%$ & $0 \%$ \\
\hline 4 & $25 \%$ & $55 \%$ & $20 \%$ & $0 \%$ & $0 \%$ \\
\hline 5 & $30 \%$ & $30 \%$ & $10 \%$ & $20 \%$ & $10 \%$ \\
\hline 6 & $45 \%$ & $45 \%$ & $10 \%$ & $0 \%$ & $0 \%$ \\
\hline 7 & $45 \%$ & $35 \%$ & $10 \%$ & $10 \%$ & $0 \%$ \\
\hline
\end{tabular}

Tabela 4: Desafios com Palitos (avaliação quantitativa de interface)

A avaliação quantitativa de interface do jogo Desafios com Palitos oportunizou perceber-se que o jogo reconheceu os toques de entradas dos jogadores, fator importante, especialmente por se tratar do jogo mobile que por vezes pode ser jogado em dispositivos com telas de tamanho pequeno.

Observou-se também que a maioria dos estudantes agradou-se das cores do jogo, bem como tiveram fácil entendimento dos ícones de representação do jogos, fator importante de acordo com a Teoria da Carga Cognitiva, abordada por [18]. 
A maioria dos estudante destacaram que o jogo dispôs de poucas informações, e as informações contidas são de fácil entendimento, esta constatação assume importante valor por se tratar de um jogo que aborda diferentes conteúdos matemáticos, e por conseguinte pode ser jogado por diferentes públicos.

Ademais, por meio das respostas, foi possível identificar que os estudantes se sentiram motivados com o jogo, ao mesmo tempo que ficaram satisfeitos com os desafios enfrentados ao longo do jogo. Esta ultima constatação assume imensa importância, pelo fato de ser sabido que é de fundamental importância que os jogos transmitam aos jogadores o sentimento de motivação no decorrer de suas jogadas.

\subsection{Avaliação Pedagógica do jogo Conquis- tando com Resto}

Observou-se que todos os estudantes utilizaram a folha de rascunho para realizar alguns cálculos necessários para a conclusão das jogadas, denotando que houve uma união entre o tradicional e o digital no sentido que os estudantes não abandonaram os mecanismos didáticos tradicionais ao mesmo tempo em que fizeram uso de um mecanismo digital contemporâneo.

De acordo com o professor que realizou a análise nos rascunhos, a maioria dos estudantes, ao se deparar com um cálculo que resultasse em um número decimal, apresentaram dificuldades em utilizar o resto da divisão, aferindo assim que os mesmos apresentam dificuldades para resolver problemas com a operação básica de divisão, sendo assim, estes estudantes buscaram fazer uso da operação inversa da divisão (multiplicação) para chegar à resolução da questão.

Pode-se perceber ainda, que a maioria dos discentes notou que seria difícil encontrar um número no dado, que apresentasse um divisor não exato para os números $24 \mathrm{e}$ 36 , fato que chamou a atenção de alguns destes estudantes, os mesmos questionaram este fato. Tal acontecimento, segundo o professor é um fato que permite ao docente esclarecer uma série de conceitos matemáticos, quando questionado em sala de aula.

O mesmo aconteceu em relação ao número zero, os estudantes chegaram a testar todas as possibilidades de divisão com relação a este número, para poder observar que é impossível a divisão por zero, somente depois de realizar todos os testes os discentes começaram a questionar este fato. Através desta percepção, foi possível diagnosticar que o jogo conseguiu abordar uma regra funda- mental da Matemática básica, cumprindo assim com seus objetivos pedagógicos abordados desde sua versão tradicional, a Figura 9 mostra os rascunhos de um estudante, que deixa claro as observações anteriormente descritas.

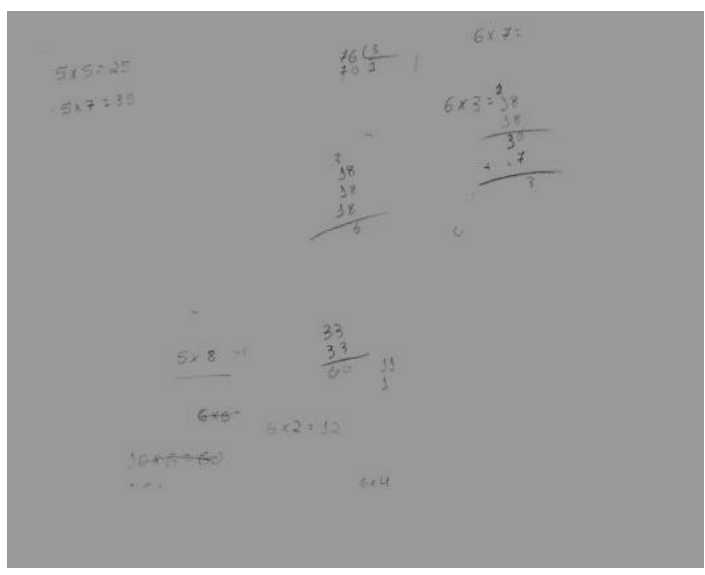

Figura 9: Conquistando com Resto: folha de rascunho

\subsection{Avaliação Pedagógica do jogo Desafios com Palitos}

A avaliação dos aspectos pedagógicos do jogo Desafios com Palitos, aconteceu de forma semelhante à avaliação do jogo Conquistando com Resto. Neste sentido, os estudantes receberam cada um, uma folha de papel, de modo a fazer uso da mesma, caso necessário para a resolução das jogadas. Além disto, houve posteriormente ao final do jogo um momento de conversação entre os estudantes e o professor de Matemática, que interagiu, especialmente, no sentido de solucionar alguns questionamentos matemáticos, realizados pelos estudantes.

Notou-se que neste jogo, o uso da folha de rascunho foi relativamente menor em relação ao jogo anterior, neste caso, os estudantes conseguiram resolver a maioria dos desafios sem o auxilio da folha de rascunho. De acordo com os profissionais que acompanharam os testes, tal fato ocorre, por neste os desafios não envolverem cálculos matemáticos, tal ocorrência é comprovada pelo fato ocorrido de que o uso da folha de rascunho foi maior, nas fases que envolviam cálculos (mesmo que de forma indireta), por exemplo, nas fases 3 e 5 que tem como desafios intrínsecos, cálculos envolvendo Algarismos Romanos.

Posteriormente, ocorreu uma reunião entre o professores que acompanharam a avaliação dos jogos e os demais envolvidos no projeto, neste momento, os mesmos tiveram a oportunidade de expressar suas opiniões a respeito dos jogos e da interação dos estudantes nestes jogos. Neste momento, uma série de aspectos foram levantados, no sentido de propor novos elementos para os jogos. 
Neste contexto, o professor avaliou de forma positiva o envolvimento dos estudantes com os jogos, de acordo com o mesmo, foi observado que os estudantes conseguiram se concentrar nos desafios e sentiram-se motivados em vencer os desafios do jogo, isto, porque, tais estudantes interagiam com os outros, e discutiam a respeito do raciocínio que cada um estava utilizando parar passar as fases do jogo.

Ainda neste contexto, observou-se que os estudantes, por vezes, tinham lapsos de entendimento de certos assuntos matemáticos, como em alguns casos onde estes estudantes observavam que determinados assuntos do jogo, poderiam ser usados em sala de aula no intuito de resolver certos assuntos abordados nas aulas tradicionais pelos seus professores, fato que permite diagnosticar que o jogo cumpre com o seu objetivo pedagógico de abordar de forma implícita, determinados conceitos matemáticos, sem que o mesmo perca sua jogabilidade.

\section{Discussões}

Em geral, os resultados mostram que os ambos os jogos cumprem com seus objetivos em relação aos critérios de usabilidade, bem como com seus objetivos pedagógicos. Ambos os jogos conseguiram abordar os assuntos propostos, de modo a manter os seus aspectos pedagógicos ao mesmo tempo, que os deixando atrelados as mecânicas contemporâneas dos jogos digitais, permitindo que seus usuários disponham de boa jogabilidade. No entanto, observou-se que o primeiro jogo manteve, uma maior sintonia entre o tradicional e o digital diante do público ao qual foi avaliado.

Ademais, o grupo de pesquisadores que realizou este trabalho, diante das lições aprendidas, sugere fortemente que possíveis trabalhos de Virtualização de Jogos, sigam as perspectivas mostradas neste trabalho, especialmente no que cerne a adoção de uma equipe de desenvolvimento multidisciplinar, contando com participação de psicólogos, pedagogos, computação (designer de interface (IHC) e programadores), além de professores da disciplina a qual o jogo seja destinado.

A união destes profissionais, é de extrema importância no intuito de manter-se os aspectos pedagógicos e psicopedagógicos do jogos, ao mesmo tempo que o mantenha atrelado a uma mecânica de games contemporânea.

Adicionalmente, no sentido da avaliação, este grupo de pesquisadores, sugere fortemente que a avaliação se preocupe com o público alvo, bem como com as interferências por parte dos professores, tomando por base a pesquisa de [8], que os professores e demais profissionais que acompanharem a avaliação, interfiram o mínimo possível nas jogadas realizadas pelos estudantes, deixando para fazer possíveis observações ao final da avaliação, momento que poderão inclusive solucionar possíveis dúvidas concernentes ao conteúdo da disciplina abordada.

Finalmente, o grupo de trabalho responsável por este trabalho, realizou uma série de minicursos abordando o tema Aprendizagem Baseada em Games, onde teve-se a oportunidade discutir a respeito dos benefícios dos jogos na educação, bem como apresentar os jogos desenvolvidos e como os mesmos podem ser aplicados aos estudantes. Estas oficinas foram direcionadas a professores do ensino básico municipal e estadual de uma série de cidades localizadas no agreste do estado de Pernambuco.

\section{Limitações}

O trabalho ora apresentado possui como algumas de suas limitações, o fato de inicialmente o processo para seleção dos jogos não ter sido completamente empírico, mesclando diferentes atividades, como revisão sistemática e opinião de especialistas, podendo assim ter deixando alguns jogos fora da realização do projeto. A quantidade de participantes da fase final de experimento $(\mathrm{N}=10)$ pode ter sido baixa, bem como, o experimento foi realizado em um ambiente controlado, e em um laboratório não localizado na escola de origem dos estudantes, podendo assim, os dados não representarem com totalidade a realidade, e reforçando a necessidade da realização do experimentos em diferentes contextos.

Além disso, por desafios de infraestrutura, ambos os jogos foram avaliados apenas em desktops, podendo assim, não ter avaliado todas a nuances dos jogos avaliados, visto que o jogo Desafios com Palitos também pode ser executado em smartphones. Não foi realizado nenhuma avaliação inicial em relação as experiências anteriores dos participantes, bem como, não foram coletadas informações referentes ao gênero dos estudantes, não podendo afirmar a quantidade de estudantes do sexo masculino e feminino, dificultado a inferência de algumas informações importantes, como dados comparativos em relação a aceitação dos jogos quanto ao gênero dos estudantes.

Um estudante que realizava a avaliação do jogo Conquistando com Resto, recusou-se a entregar sua folha de rascunho (mesmo destacando-se que não seria necessário colocar o nome e que a análise de cada folha, aconteceria sem identificação do estudante), impendendo que sua folha de rascunho pudesse ser analisada, e prejudicando a identificação e analise de dados inerentes a pesquisa.

Finalmente, em relação a equipe que participou, a mesma foi modificada durante o processo de desenvolvimento e avaliação dos jogos, bem como, alguns participantes saíram 
da equipe durante o processo de desenvolvimento do projeto.

\section{Considerações Finais}

Como afirma [1], [33], e [13] entre outros, o uso de jogos já esta cunhado como um artefato que se bem desenvolvido e bem aplicado, auxilia de forma grandiosa os processos de ensino e aprendizagem, sendo colocado como uma alternativa capaz de motivar, engajar, avaliar, ou mesmo preparar os estudantes, não somente no cerne dos conteúdos vislumbrados nos currículos escolares, mas também em toda a vida cotidiana dos mesmos.

Neste contexto, é notório também, que existe uma série de contrapontos nos aspectos relacionados ao desenvolvimento e aplicação destes jogos, de acordo com [8] e [24], sabe-se que se os mesmo não forem desenvolvidos e aplicados de acordo com metodologias que promovam o ensino e aprendizagem, os resultados poderão não ser satisfatórios. Ademias, quando os professores levam para a sala de aula, jogos tradicionais, que fujam da realidade digital dos estudantes, não terão o seu convite ao jogo aceito pelos estudantes, muitas vezes causando um sentimento de frustração.

Neste sentido, a Virtualização de Jogos apresenta-se como uma alternativa capaz solucionar esta problemática, sendo esta responsável por atrelar os conceitos e paradigmas pedagógicos e psicopedagógicos da versão tradicional de um jogo, a elementos contemporâneos dos jogos digitais, promovendo assim uma união entre o tradicional e o digital.

Assim, este trabalho promoveu um mapeamento entre jogos tradicionais e jogos digitais usados na disciplina de Matemática, por meio de pesquisa acadêmica, pesquisa web e pesquisa ao livro acadêmico, bem como a participação de profissionais de Matemática, Pedagogia, Psicologia e Computação. Separou-se ainda, oito jogos tradicionais usados com eficácia na disciplina de Matemática e que não haviam sido recriados em versão digital.

Nesta perspectiva, sequencialmente, escolheram-se dois jogos para serem submetidos ao processo de virtualização, os mesmos foram virtualizados por uma equipe multidisciplinar, agregando aspectos pedagógicos e psicopedagógicos, correlacionado aos descritores de Matemática, possibilitando que os jogos virtualizados, fossem validados em sala de aula, por estudantes da educação básica sob a observação de seus professores e dos profissionais participantes deste trabalho.

Neste sentido, os resultados obtidos oportunizaram perceber que os jogos foram aceitos de forma positiva no contexto de estudantes e professores, percebeu-se também que os jogos foram avaliados de forma positiva em relação aos seus aspectos computacionais, de interface (usabilidade), bem como em sua estrutura pedagógica matemática.

Os resultados obtidos permitiram ainda, destacar a Virtualização de Jogos, como um processo capaz de atrelar os princípios pedagógicos e psicopedagógicos dos jogos tradicionais as mecânicas contemporâneas dos jogos digitais, sendo o mesmo capaz de atrelar o tradicional e o digital, em favor dos processos de ensino e aprendizagem.

Neste contexto, espera-se ainda com os resultados obtidos, fomentar a Virtualização de Jogos como um recurso educacional capaz de unir os aspectos tradicionais aos aspectos digitais em favor da educação, estimulando o uso de jogos na educação, de modo especial na disciplina de Matemática, alvo desta pesquisa.

Finalmente, desafia-se como trabalhos futuros vivenciar novos experimentos em diferentes ambientes para estes jogos, tal como, mensurar o engajamento, motivação e experiência de fluxo dos estudantes durante uso dos jogos. Submeter outros jogos tradicionais de diferentes disciplinas ao Processo de Virtualização de Jogos, além de os submeter a diferentes processos de avaliação. Finalmente, objetiva-se ainda, baseado nas experiências obtidas com este estudo, propor uma metodologia para Virtualização de Jogos Educativos, bem como para a avaliação de jogos desenvolvidos baseados nesta metodologia.

\section{Referências}

[1] Alves, L. Game Over: Jogos e violência. 1 1 . ed. São Paulo: Futura 2005.

[2] Araujo, A. L. S. O.; Scaico, P. D. Aplicação da Taxonomia de Bloom no ensino de programação com Scratch. In: Workshop de Informática na escola. 24a ed. 2013. Campinas - São Paulo.

[3] Araújo, B. M. R.; Freitas, C. M. S. M.; Caminha, I. O.; Silva, P. P. C. Virtualização esportiva e os novos paradigmas para o movimento humano. Revista Motriz. Vol. 17, n. 4, 2011.

[4] Cabreira, L. G., Aquino, O. R. Jogos eletrônicos a virtualização do brincar na perspectiva dos professores de $3^{\mathrm{a}}$ e $4^{\mathrm{a}}$ séries do ensino fundamental I de uma escola particular de Maringá/PR, In: Educação em Revista 7 ed. p. 85-102, São Paulo. 2006. 
[5] Carissimi, A. Virtualização: Princípios básicos e aplicações.Minicurso da $9^{\text {a }}$ Escola Regional de Alto Desempenho-ERAD, p. 39-69. 2009.

[6] Cybis, W., Betiol, A. H., \& Faust, R. Ergonomia e usabilidade: conhecimentos, métodos e aplicações. Novatec Editora. 2007.

[7] de França, R. S., \& da Silva, A. C. B. Avaliação de softwares educativos para o ensino de Língua Portuguesa. Revista Brasileira de Informática na Educação, 22(03), 23. 2014.

[8] Falkembach, G. A. M. O Lúdico e os Jogos Educacionais. Revista Mídias na Educação CINTEDUFRGS, Rio Grande do Sul. 2007.

[9] Hartson, H.R. Human-Computer Interaction: Interdisciplinary roots and trends". In: The Journal of System and Software, 43, 10-118. 1998.

[10] Huizinga, J. Homo ludens: o jogo como elemento da cultura. $2^{a}$ ed. São Paulo: perspectiva, 1980.

[11] Karat, J. The cost-benefit and business case analysis of usability engineering. InterChi '93, Amsterdam, Tutorial Notes 23. 1993.

[12] Likert, R. A technique for the measurement of attitudes. Archives of psychology.1932.

[13] Mattar, J. Games em educação: como os nativos digitais aprendem. Pearson Prentice Hall, São Paulo, p. 144. 2008.

[14] Moran, T. The Command Language Grammars: a representation for the user interface of interactive computer systems. International Journal of ManMachine Studies 15:3-50, Academic Press. 1981.

[15] Mussoi, E. M., Flores, M. L. P., \& Behar, P. A. Avaliação de objetos de aprendizagem. In: Congresso Iberoamericano de Informática Educativa, Santiago, Chile. Anais. 2010.

[16] Neto, J. F. B.; da Fonseca, F. D. S. Jogos educativos em dispositivos móveis como auxílio ao ensino da matemática. In: Revista Novas Tecnologias na Educação (RENOTE), 11(1). 2013.

[17] Nielsen, J. Usability engineering. Elsevier. 1994.

[18] Nunes, M.; Giraffa, L. A educação na ecologia digital. PPGCC/ FACIN, PUCRS. 2003.
[19] Piaget, J. A formação do símbolo na criança. Rio de Janeiro. Ed. Zahar.1978.

[20] Preece, J.; Rogers, Y.; Sharp, E. Interaction Design: Beyond Human-computer Interaction. New York, NY: John Wiley \& Sons. 2002.

[21] Prates, R. O., \& Barbosa, S. D. J. Avaliação de Interfaces de Usuário-Conceitos e Métodos. In: Jornada de Atualização em Informática do Congresso da Sociedade Brasileira de Computação, Capítulo (Vol. 6). 2003

[22] Ribeiro, A., L. (2012) Jogos digitais online: ampliando o(s) Letramento(s) na sala de aula. In: V Simpósio Hipertexto e tecnologias na educação. Recife - PE.

[23] Rieder, R., Zanelatto, E. M., \& Brancher, J. D. Observação e análise da aplicação de jogos educacionais bidimensionais em um ambiente aberto. INFOCOMP: Journal of Computer Science, 4(2), 63-71. 2005

[24] Santos, W. O.; da Silva, A. P.; Silva Junior, C. G. Conquistando com o Resto: Virtualização de um Jogo para o Ensino de Matemática. In: Anais do XXV Simpósio Brasileiro de Informática na Educação (SBIE). Dourados - MT p. 317-321. 2014.

[25] Santos, W. O., Souza, A. A., Oliveira, M. L. S., Silva, A. P., Tenório, A. K. S., Rodrigues, A. N., Silva Junior, C. G. Desafios com Palitos: Processo de Desenvolvimento de um Jogo Educativo. In: XIII Simpósio Brasileiro de Jogos e Entretenimento Digital (SBGames). Porto Alegre - RS. 2014.

[26] Santos, W. O., Silva Junior, C. G. Uso de Jogos no ensino da Matemática: Uma análise entre os jogos tradicionais e os jogos digitais, baseada em pesquisa e mapeamento dos materiais encontrados na Web. In: X Seminário Jogos Eletrônicos, Educação e Comunicação. Salvador - BA. 2014.

[27] Santos, W. O., Silva Neto, S. R., I., I., Bittencourt, Silva Junior, C. G. Avaliação de Jogos Educativos: Uma Abordagem no Ensino de Matemática. In: Anais do XXVI Simpósio Brasileiro de Informática na Educação (SBIE). Maceió - AL. 2015.

[28] Santos, W. O., Silva Neto, S. R., Silva Junior, C. G. Uso de Games no ensino da Matemática. Uma proposta de virtualização dos jogos tradicionais, para uso como mecanismo de apoio ao processo de ensino e aprendizagem. In: V Simpósio Hiper- 
texto e Tecnologias na Educação, Recife - PE, p.

216. 2013.

[29] Silva, E. T. Criticidade e leitura: ensaios. São Paulo: Mercado de Letras: Associação de Leitura do Brasil (ALB). 1998.

[30] Silva Neto, S. R., Santos, W. O, Silva Junior, C. G. Games no ensino da Matemática. Processos de virtualização de Jogos para uso entre estudantes e professores da região Agreste do estado de Pernambuco. In: V Simpósio Hipertexto e Tecnologias na Educação, Recife - PE, p. 216. 2013.

[31] Silva Neto, S.R., Santos, H. R. M., DE Souza, A. A., Santos, W. O. Jogos Educacionais como Ferramenta de Auxílio em Sala de Aula. In: XIX Workshop de Informática na Escola, 2013.

[32] Sommerville, I. Engenharia de Software, $8^{\mathrm{a}}$ ed. Pearson Addison-Wesley. 2007

[33] Tarouco, L. M. R.; Konrath, M., L., P.; Grando A., R., S. O aluno como co-construtor e desenvolvedor de jogos educacionais. Revista Novas Tecnologias na Educação (RENOTE). V. 3. No. 2. Rio Grande do Sul, Novembro. 2005.

[34] Togni, A. C., Rehfeldt, M. J. H., Bersch, M. E., Thomas, M. I. P., Poletti, C. F., \&

[35] Kronbauer, K. A. Piff geométrico: um objeto virtual de aprendizagem para o ensino de ciências exatas. Revista Novas Tecnologias na Educação (RENOTE)., V. 7, N. 3, p. 45-52, 2009.

[36] Vergnaud, G. A Comprehensive Theory of Representation for Mathematics education Journal or Mathematical Behavior, V 17, N 2, pp.167-181. 1997.

[37] Vygotsky, L. S. Pensamento e linguagem. $1^{\text {a }}$ ed. P. 135. 1987.

[38] Zem-Lopes, A., M.; Pedro, L., Z.; Andrade, F., R., H.; Borges, S., S.; Isotani, S. Tecnologias da Web Semântica em Ambientes Educacionais: uma Revisão Sistemática In: XXIV Simpósio Brasileiro de Informática na Educação (SBIE) Campinas SP. 2013.

[39] Zorzal, E. R., Kirner, C., Cardoso, A., Lamounier JR, E., de Oliveira, M. R. F., \& Silva, L. F. (2008). Ambientes Educacionais Colaborativos com Realidade. Aumentada. In: Revista Novas Tecnologias na Educação (RENOTE), v.6 n.1. 